\title{
Temporary placement of a covered metal stent for the management of a bleeding aortoesophageal fistula
}

An aortoesophageal fistula is a life-threatening cause of gastrointestinal bleeding [1-3]. Until now, temporary endoscopic hemostatic treatment for a bleeding aortoesophageal fistula prior to definitive treatment has been a great challenge because the endoscopic procedure that is conventionally used for this condition is not always effective [3-5]. We report here a patient with a bleeding aortoesophageal fistula in whom temporary hemostasis was successfully achieved using a covered metal stent.

A 35-year-old woman presented with anterior chest pain and melena, 12 days after she had eaten a fish and developed a foreign-body sensation in her throat. She visited a primary-health clinic, where she underwent an endoscopic examination which revealed a "V"-shaped fish bone stuck in her cervical esophagus. Because it was not possible to withdraw the fish bone with forceps, her primary-care physician pushed the fish bone forcibly down into her stomach.

One day before her admission to our unit, the patient complained of anterior chest pain and melena. Computed tomography of her chest revealed a pseudoaneurysm on the aortic arch, approximately $2 \mathrm{~cm}$ in size. Upper endoscopy was performed in order to evaluate the esophagus and active spurting of blood was noted $22 \mathrm{~cm}$ from the incisors (Figure $\mathbf{1} \mathbf{a}$ ). It was impossible to manage this using a conventional hemostatic procedure because of the massive bleeding, which entirely filled the esophagus. We therefore decided to insert a covered stent in an attempt to control the bleeding from the aortoesophageal fistula. First, a guide wire was inserted beside the scope, and then a covered, 10-mm-long Ultraflex esophageal stent (Boston Scientific Microvasive, Natick, Massachusetts, USA) was promptly inserted (Video 1). The covered stent was released under endoscopic guidance. After the stent was fully expanded there was no further bleeding in the esophagus (Figure 1 b). During and after the proce-

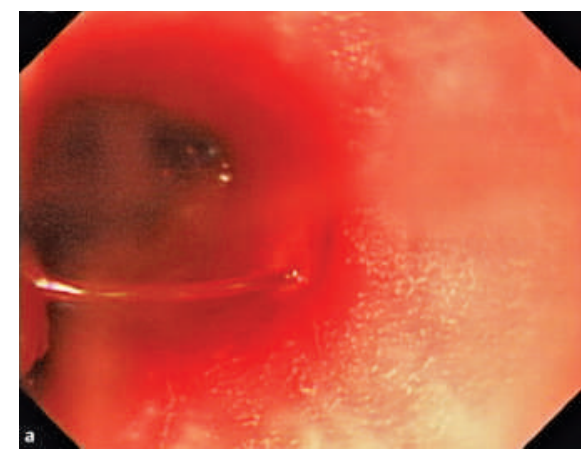

Acknowledgment

This case is to be presented as a video forum at Digestive Disease Week 2006, 20 25 May 2006, Los Angeles, California, USA.

Endoscopy_UCTN_Code_TTT_1AO_2AZ

D. H. Park, J. H. Park, S.-H. Lee, S.-H. Park, H.-S. Kim, S.-J. Kim

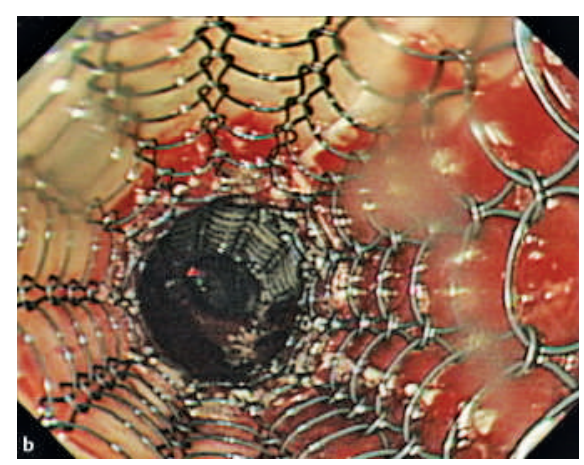

Figure 1 Endoscopic view showing active spurting of blood, $22 \mathrm{~cm}$ from the incisors (a). The bleeding site seemed to be a protruding lesion with a central fistula. After full expansion of the stent there was no further bleeding in patient's esophagus (b).

dure the patient's vital signs were satisfactory, and 6 hours after stent placement she underwent definitive surgery to correct the aortoesophageal fistula.

Prompt endoscopic placement of a covered esophageal stent for the treatment of a bleeding aortoesophageal fistula may play a role as "salvage therapy" before definitive treatment of this life-threatening condition.
Division of Gastroenterology,

Department of Internal Medicine, Soon Chun Hyang University Cheonan Hospital, Cheonan, Korea.

\section{Video}

Active spurting of blood was noted $22 \mathrm{~cm}$ from the incisors during esophagoscopy. A covered esophageal stent was promptly inserted and released under endoscopic guidance. After the stent was fully expanded there was no further bleeding in the esophagus.

online content including video sequences viewable at:

www.thieme-connect.de/ejournals/abstract/ endoscopy/doi/10.1055/s-2006-944600 


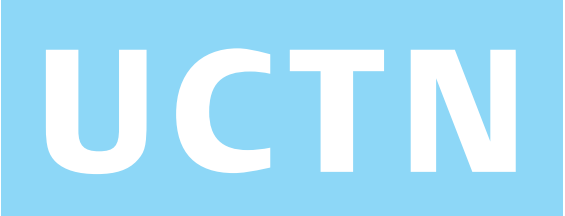

References

${ }^{1}$ Chaikitpinyo A, Panamonta M, Sutra S et al. Aortoesophageal fistula: a life-threatening cause of upper gastrointestinal hemorrhage in double aortic arch, a case report. J Med Assoc Thai 2004; 87: 992 - 995

${ }^{2}$ Heckstall RL, Hollander JE. Aortoesophageal fistula: recognition and diagnosis in the emergency department. Ann Emerg Med 1998; 32: $502-505$

${ }^{3}$ Martin M, Steele S, Mullenix P et al. Endoscopic diagnosis of a clinically silent aortoesophageal fistula: case report and review of the literature. Ann Vasc Surg 2004; 18: $352-356$

${ }^{4}$ Flores J, Shiiya N, Kunihara T et al. Aortoesophageal fistula: alternatives of treatment case report and literature review. Ann Thorac Cardiovasc Surg 2004; 10: 241 - 246

${ }^{5}$ Lee OJ, Kim SH. Aortoesophageal fistula associated with tuberculous mediastinitis, mimicking esophageal Dieulafoy's disease. J Korean Med Sci 2002; 17: 266-269
Corresponding author

\section{H. Park, M.D.}

Division of Gastroenterology, Department of Internal Medicine Soon Chun Hyang University Cheonan Hospital 23-20 Bongmyung-dong Cheonan 330-721 Republic of Korea Fax: $\quad$ +82-41-574-5762 Email: dhpark@schch.co.kr 